\title{
Morphological, structural, compositional properties and IR-spectroscopy of CdSe films deposited by close-spaced vacuum sublimation
}

\author{
M.M. Ivashchenko ${ }^{\text {a, }}{ }^{\text {, }}$ A.S. Opanasyuk ${ }^{\text {b }}$, V.I. Perekrestov ${ }^{\text {b }}$, V.V. Kosyak ${ }^{\text {b }}$, Yu.P. Gnatenko ${ }^{\text {, }}$, \\ V.M. Kolomiets ${ }^{\mathrm{d}}$ \\ ${ }^{a}$ Konotop Institute, Sumy State University, Myru Ave. 24, UA-41600 Konotop, Ukraine \\ b Sumy State University, Rimsky-Korsakov Str. 2, UA-40007 Sumy, Ukraine \\ ${ }^{\mathrm{c}}$ Institute of Physics of National Academy of Sciences of Ukraine, Nauky Ave. 46, UA-03028 Kyiv, Ukraine \\ ${ }^{\mathrm{d}}$ Institute of Applied Physics of National Academy of Sciences of Ukraine, Petropavlivska Str. 58, UA-40030 Sumy, Ukraine
}

\section{A R T I C L E I N F O}

\section{Article history:}

Received 31 December 2014

Received in revised form

23 April 2015

Accepted 24 April 2015

Available online 7 May 2015

\section{Keywords:}

Cadmium selenide

Thin films

Surface morphology

X-ray diffraction analysis

RBS

FTIR

\begin{abstract}
A B S T R A C T
The polycrystalline CdSe films were deposited by the close-spaced vacuum sublimation technique at the different substrate temperatures (373-873 K). Surface morphology, grain size and growth mechanism of the films were determined by the scanning electron microscopy. The X-ray diffraction analysis of structural and sub-structural properties of the films was carried out to study their phase composition and growth texture. The main structural parameters of thin films, such as texture, lattice parameter, grain size, scattering domain size and micro-stress level have been determined in the work depending on the condensation film conditions. RBS and FTIR analysis shows that obtained films in general are homogenous and pure. As a result, the growth conditions of CdSe polycrystalline films with good crystal quality were determined.
\end{abstract}

() 2015 Elsevier Ltd. All rights reserved.

\section{Introduction}

The cadmium selenide films are being intensively investigated as a material for the production of the base layer of tandem solar cells [1-3], photo-detectors [4,5], high-performance thin-film transistors [6,7], electrochemical cells [8], photovoltaic devices [9-11], etc.

In order to effectively use CdSe films in microelectronics it is necessary to optimize their structural, optical and electrical properties. It is well known that above mentioned properties depend on thin films deposition method and growth conditions [9]. Currently, the magnetron sputtering [10] and chemical methods, namely chemical bath [11-13], photochemical [14], and electrochemical deposition $[15,16]$ etc., are the most used techniques for growth of CdSe films. In most cases the crystal quality of CdSe thin films

\footnotetext{
* Corresponding author. Tel.: +380 98 4302003; fax: +380 544725171.

E-mail addresses: m_ivashchenko@ukr.net (M.M. Ivashchenko), v_kosyak@ukr. net (V.V. Kosyak).
}

deposited by these methods is rather low (small grain size, high concentrations of the extended defects and high level of microstrain) [11,12]. The modifications of the thermal vacuum deposition method such as hot-wall epitaxy and isothermal close-spaced sublimation allow to obtaining CdSe thin films with improved crystal properties [17-23]. Due to the technical features of the evaporator, close-spaced vacuum sublimation (CSVS) method [24] could be considered as a promising low-cost technique for the deposition of the high crystal quality CdSe thin films. This method is widely used for the deposition of the II-VI compound thin films under conditions close to thermodynamic equilibrium growth [24-27]. Unfortunately, this technique doesn't allow to obtain films at room temperature deposition conditions due to the constructional features of evaporator [24]. The possible way of this problem solution is in additional thermal shields' usage.

It should be noted, that the photovoltaic properties of $\mathrm{ZnTe} / \mathrm{CdTe}$ and $\mathrm{ZnS} / \mathrm{CdTe}$ hetero-structures were studied by us in Ref. [27]. It was shown that these structures based on CdTe layer are useful for photovoltaic device fabrication. In future we assume to study the $\mathrm{ZnTe} / \mathrm{CdSe}$ hetero-structure due to the minimal value of the lattice 
mismatch between both layers' materials $(\delta \sim 0.5 \%)$. Earlier, the working parameters and defect structure of $\mathrm{ZnTe} / \mathrm{CdSe}$ heterostructures were estimated by us using theoretical modeling [28]. Besides, in Refs [24-27,29] were studied structural, optical and luminescence properties of CdTe, ZnTe and ZnS films obtained by SCVS technique at similar deposition conditions, suitable for use as the basis layers of high efficiency photo-detectors.

Presently, the structural properties of CdSe polycrystalline thin films prepared by CSVS method have been studied only in a few papers [21-23]. The main goal of the present paper is to investigate the influence of growth conditions on structural, micro-structural parameters of CdSe films obtained by the CSVS method in order to optimize deposition process of thin layers with improved crystal quality.

\section{Experimental details}

The CdSe thin films were deposited by the CSVS technique (the description of the equipment for the deposition presented in Ref. [24]) on cleaned glass substrates from stoichiometric CdSe powder using the following growth conditions: evaporator temperature $T_{e}$ was kept constant at $973 \mathrm{~K}$, substrate temperature $T_{S}$ was varied from 373 to $873 \mathrm{~K}$ and deposition time $t$ was $10 \mathrm{~min}$.

The surface morphology of the films has been investigated by the scanning electron microscopy (SEM). Average grain size $(d)$ in the layers was estimated by Jeffries method [30]. In order to study the optical (FTIR) parameters the thin films with thickness $l$ of about $0.8 \mu \mathrm{m}$ were used, and for the structural investigations thicker films $l=5 \mu \mathrm{m}$ were studied.

The X-ray diffraction (XRD) analysis was carried out by DRON407 equipment with a conventional Bragg-Brentano $\theta-2 \theta$ geometry ( $2 \theta$ is the Bragg's angle) using Ni-filtered $\mathrm{CuK}_{\alpha}$ radiation. The samples were measured in the $2 \theta$ - angle range from 20 to $80^{\circ}$.

The peak intensities were normalized to the intensity of (002) peak of the hexagonal phase. Phase analysis was performed by comparison of the inter-planar distances as well as relative intensities measured from the samples and reference Joint Committee on Powder Diffraction Standards (JCPDS) data [31].

The texture of the films was determined by the Harris method [32]. The pole density was calculated as: $P_{i}=\left(I_{i} / I_{0 i}\right) /(1 / N) \sum_{i=1}^{N}\left(I_{i} / I_{0 i}\right)$, where $I_{i}, I_{0 i}$ are the integral intensities of $i$-diffraction peak for the film and reference powder sample of CdSe, respectively, $N$ is a number of lines observed in the XRD pattern. The orientation factor was found using the following equation: $f=\sqrt{(1 / N) \sum_{i=1}^{N}\left(P_{i}-1\right)^{2}}$.

The scattering domain (SD) size $L$ and micro-strains level $\varepsilon$ were determined from the broadening of the XRD peaks. Cauchy and Gaussian approximations were used to separate physical and instrumental contributions to peaks broadening [33,34]. In order to separate the contributions in physical broadening from the dispersive structure of the films and micro-deformation the Hall approximation was applied [33]. Besides that, micro-strains level and SD size were calculated by the method based on threefold convolution of XRD line [24,25]. Lattice parameters of the wurtzite and sphalerite phases were calculated by the Nelson-Riley extrapolation method [33,34]. The lattice parameters $a(c)$ of the hexagonal phase were determined by the graphical convergence method (line extrapolation).

RBS measurements with helium ions have been carried out using an accelerator with energy of $1.8 \mathrm{MeV}$. RBS spectra were obtained in a vacuum chamber under $\varphi=165^{\circ}$ scattering angle using a surface-barrier detector. The spectra were evaluated by SIMNRA 6.0 program.
The ratio of atomic concentrations in the elements of CdSe compound had been measured by the position of the partial peaks maxima using the following equation:

$\gamma=C_{C d} / C_{S e}=\left(\sigma_{S e} H_{C d} \Delta E_{C d}\right) /\left(\sigma_{C d} H_{S e} \Delta E_{S e}\right)$

where $\sigma_{C d}, \sigma_{S e}$ are the scattering cross-sections of the charged particles by the atoms of cadmium and selenium; $H_{C d}, H_{S e}$ are the values of the corresponding signals in the spectra; $\Delta E_{C d}, \Delta E_{C d}$ are the corresponding energy peaks widths [35].

Infrared (FTIR) spectra of the films deposited on glass-ceramic substrates were estimated by Fourier-transform infrared (FTIR) Agilent Cary 630 spectrometer. FTIR spectra were obtained in fullrefraction regime (Diamond ATR appliance). The optical range of absorbance was changed from 4000 up to $400 \mathrm{~cm}^{-1}$.

\section{Results and discussion}

\subsection{Films morphology}

The SEM study has showed that the growth mechanism of CdSe films is similar to other chalcogenide thin films [19,20,25]. Namely, it was observed that grain (crystalline) size is increased with the substrate temperature from about $d=0.1 \mu \mathrm{m}$ at $T_{s}<673 \mathrm{~K}$ (Fig. $1 \mathrm{~b}$, d) to $d=3.0 \mu \mathrm{m}$ at $T_{s}=873 \mathrm{~K}$ (Fig. $1 \mathrm{a}, \mathrm{c}$ ). At low-temperature range $\left(T_{s}<673 \mathrm{~K}\right)$ thin films growth occurs via a layer-by-layer mechanism which changes to columnar growth and have a strongly pronounced pyramidal relief at higher substrate temperatures. Hence, at low-temperature range the grain size does not depend on films thickness $l$ and varies only with substrate temperature. Whereas, at high-temperature range the grain size is increased and that depends on substrate temperature and thin films thickness.

\subsection{Phase composition and texture}

The X-ray diffraction patterns of CdSe films obtained at different substrate temperatures are shown in Fig. 2. As follows from analysis of XRD patterns the layers are characterized by (002), (112) or (110) growth textures.

The calculations of the pole density $P_{(\mathrm{hkl})}$ allowed to determine [002] axial growth texture in CdSe layers obtained at $T_{s} \leq 773 \mathrm{~K}$. The perfection of [002] texture depends on growth conditions and increase with the films thickness. This texture is changed to [102] in the films obtained at higher temperature, namely at $T_{s}=873 \mathrm{~K}$. It should be noted that [002] axial texture is typical for wurtzite II-VI films deposited by thermal evaporation $[22,36]$. We assume that texture of the low-temperature condensates was formed due to free energy minimum of condensate-substrate interface, which promote formation of the (002) closest-packed plane. Also, it is well known (Ref. [37]) that in the case of the hexagonal lattices the strongest chemical bonds are realized by atoms placed in semicrystal configuration on the crystallographic planes (110) or (101). Thus, at higher substrate temperatures when growth conditions are close to thermodynamic equilibrium, the growth surface consists mainly of (110) or (101) planes. From our point of view, this leads to transition of growth texture from [002] to [102] in the samples obtained at high substrate temperature. It should be noted that, the [110], [112] growth textures were observed in CdSe films deposited by thermal evaporation [13].

The substrate temperature dependence of the orientation factor $f$ has a complex behavior (Fig. 3). Generically, the texture quality of the CdSe films decreases with the temperature. However, wave shaped $f-T_{S}$ curve shows two minimums at $570 \mathrm{~K}$ and $870 \mathrm{~K}$. Similar behavior of $f-T_{S}$ dependencies was observed in Refs. [24,38] in the case of CdTe films. The authors assumed that the minimums 

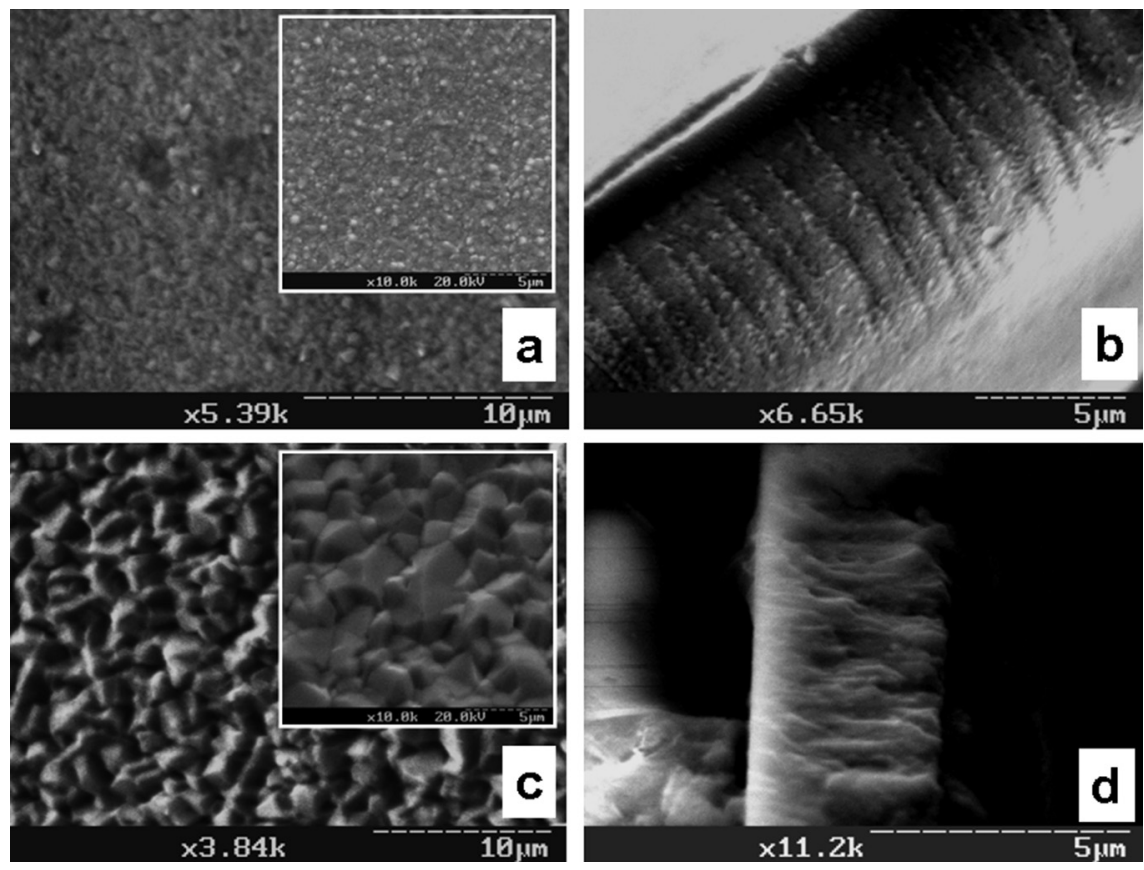

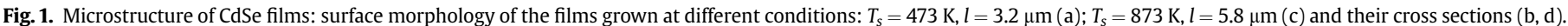

on $f-T_{S}$ curve could be explained by the change in growth mechanism at corresponding temperatures.

In most cases the II-VI films contain several phases [2,7]. The transition from meta-stable to stable phase leads to substantial changes in optical and electrical parameters of thin films. Hence, in order to produce a high-performance electronic device it is
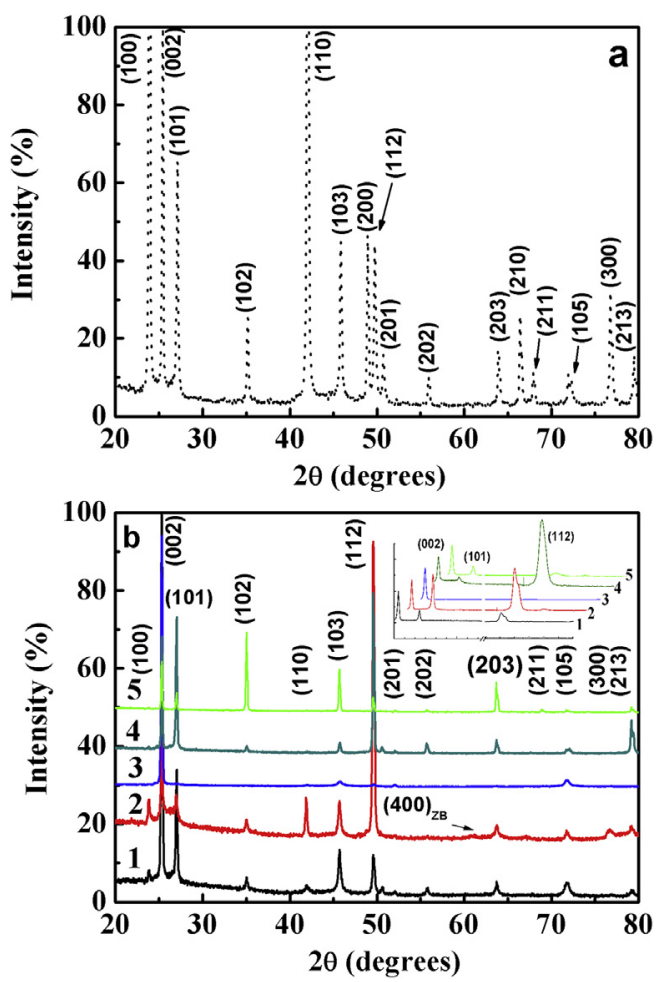

Fig. 2. X-ray patterns of CdSe powder (a) and films (b) obtained under different condensation temperatures (Fig. 2b): $T_{s}$, K: 373 (1); $473 \mathrm{~K}(2) ; 573 \mathrm{~K}(3) ; 773 \mathrm{~K}(4)$; $873 \mathrm{~K}(5)$. necessary to obtain single-phase films with the stable crystalline modification.

Detection of meta-stable cubic phase in CdSe films is complicated because most of diffraction peaks from sphalerite and wurtzite phases are coincide. For the thin films obtained at lowtemperature range $\left(T_{S}=(373-473) \mathrm{K}\right)$ the diffraction peaks from cubic phase (400) were observed (Fig. 2) at $2 \theta$ angles of $60.90^{\circ}$. The value of the lattice constant $a=(0.60746-0.60795) \mathrm{nm}$ of cubic phase calculated from this reflection is in a good agreement with the reference JCPDS data $(a=0.60770 \mathrm{~nm})$ [31]. This indicates that thin films obtained at low temperature are bi-phase with low cubic phase contribution ( $3 \%)$. However, the samples deposited at higher substrate temperature $\left(T_{S} \geq 573 \mathrm{~K}\right)$ contain only wurtzite phase. It should be noted that, as a rule, the thermally evaporated CdSe films have hexagonal structure $[18,21,22,36,39]$. The bi-phase structure of the CdSe films obtained at $T_{S}=493 \mathrm{~K}$ was observed only in Ref. [40].

In some cases, a line of low intensity of unknown origin was discovered near $52^{\circ}$. The same line can be seen on X-ray patterns presented in works [39-41], but its nature was not discussed.

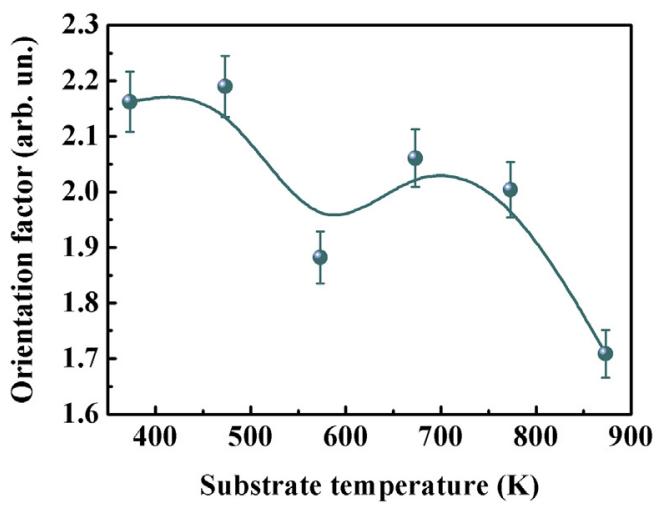

Fig. 3. Influence of substrate temperature on orientation factor. 


\subsection{Lattice parameters}

The lattice parameter of II-VI compounds is extremely sensitive to deviation from stoichiometry and to presence of impurities, oxidation, etc. That is why the precise measurements of the lattice parameter provide better understanding of above mentioned processes. The lattice parameters of initial charge and samples obtained under different growth conditions were determined by the XRD method. Calculation of $a, c$ hexagonal phase lattice parameters was performed by taking into account position of $K_{\alpha 1}$ component of all most intensive XRD lines using the following equations:

$a=\frac{\lambda}{2 \sin \theta} \sqrt{\frac{4}{3}\left(h^{2}+h k+k^{2}\right)+\left(\frac{a}{c}\right)^{2} l^{2}}$

$c=\frac{\lambda}{2 \sin \theta} \sqrt{\frac{4}{3}\left(\frac{c}{a}\right)^{2}\left(h^{2}+h k+k^{2}\right)+l^{2}}$

where, the $c / a$ ratio is related to lattice parameter of the ideal wurtzite lattice $(c / a=1.633)$.

Also, $a$ and $c$ constants were defined more precisely by Nelson-Riley method in accordance with procedure discussed in Ref. [30]. The analysis of the obtained results shows that (002), (103) and (105) XRD peaks are most suitable for determination of the $c$ lattice parameter. Whereas, the (100), (101), (110), (112), (201), (202), (300) and (213) XRD peaks were used to determine $a$ constant. Corresponding ratio $c / a(a / c)$ was used for determination of lattice parameters in equations (2) and (3). After that the calculation procedure has been repeated several times (from 3 to 5), till values $a, c$ and $c / a$ will became constant. Obtained parameters were used to calculate volume of lattice cell by the next equation: $V=3 \sqrt{3} a^{2} c$.

The obtained $a, c$ and $a / c$ constants after different number of iterations are listed in Table 1 . The increase in iteration number leads to increase in lattice parameter $a$, and to decrease in $c / a$ ratio. The experimental values of lattice parameters measured for CdSe charge ( $a=0.42983 \mathrm{~nm}, c=0.70116 \mathrm{~nm}$ ) (Fig. 4) are in a good correlation with the JCPDS reference data $(a=0.42990 \mathrm{~nm}$, $c=0.70100 \mathrm{~nm})$ [31]. At the same time, the lattice parameters $(a=(0.43036-0.43166) \mathrm{nm}$ and $c=(0.69987-0.70246) \mathrm{nm})$ (Fig. 4) determined for the thin films, are larger than the reference data. However, these results are in good agreement with the results $(a=(0.42810-0.43040) \mathrm{nm} ; c=(0.69810-0.70200) \mathrm{nm})$, obtained in work [41] by Nelson-Riley method for vacuum deposited films. It should be noted that the values of $a$ and $c$ obtained in present work using iteration method are more precise than given in Ref. [42].

As follows from Table 1 the influence of substrate temperature on lattice parameters of CdSe films shows no clear trend, which could be explained by deviations from stoichiometry of the compound. As the substrate temperature changes in a broad range from

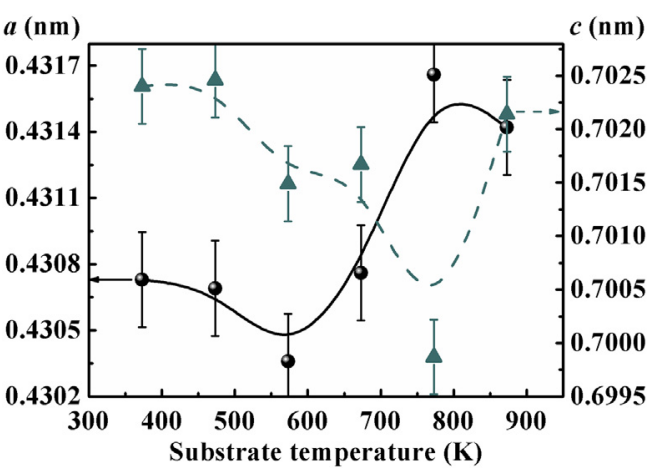

Fig. 4. The substrate temperature dependence of the lattice parameters of CdSe films.

$373 \mathrm{~K}$ to $773 \mathrm{~K}$, a considerable increase of lattice parameters takes place (Table 1). This effect may be caused by deformation of the crystal lattice due to the formation of the intrinsic point defects during the selenium re-evaporation.

In our work [43] were studied the low-temperature photoluminescence (PL) properties of CdSe films obtained at different substrate temperatures. As a result of these investigations, it was found that the PL spectrum of the films deposited at $T_{S}=873 \mathrm{~K}$ exhibit sharp intense donor bound exciton $\mathrm{D}^{0} \mathrm{X}$-line, which is characteristic for CdSe single crystals of $n$-type, as well as other bands caused by donor-acceptor emission with the participation of $\mathrm{Na}(\mathrm{Li})$ residual impurities. The presence of excitonic emission indicates the high optical quality of the investigated films. It provides a way to improve structural properties of polycrystalline CdSe films deposited on a glass substrate which is transparent for CdSe intrinsic emission to obtain high optical quality films suitable for optoelectronic and photovoltaic applications.

\subsection{Micro-stresses and micro-domains}

The average SD size $L$ and micro-stress level $\varepsilon$ were estimated from physical broadening of (100)-(200), (101)-(202) and (002)-(105) hexagonal phase XRD peaks. This allows us to determine SD size from broadening of XRD peaks of planes (002)-(105) and (100)-(200) parallel and perpendicular to the axis $c$, respectively. It was difficult to find pairs of XRD reflections which correspond to the parallel planes. That is why the low angle (002)-(105) XRD peaks at $25^{\circ}$ were used for SD size calculations.

The typical Hall graphs are presented in Fig. 5. These results were obtained with using Cauchy and Gaussian approximations and are presented in Table 2 .

It is well known that for determination of SD size and microstress level the technique based on three-hold convolution is more precise than the conventional Hall approximation method. Therefore, sub-structure parameters were obtained with aid the

Table 1

Values of CdSe lattice constants estimated by Nelson-Riley method.

\begin{tabular}{|c|c|c|c|c|c|c|c|c|c|c|}
\hline \multirow[t]{2}{*}{$T_{s}(\mathrm{~K})$} & \multicolumn{3}{|c|}{ 1st Iteration } & \multicolumn{3}{|c|}{ 3rd Iteration } & \multicolumn{3}{|c|}{ 5th Iteration } & \multirow[t]{2}{*}{$V \times 10^{28}\left(\mathrm{~m}^{3}\right)$} \\
\hline & $a$ & c & $c / a$ & $a$ & $c$ & $c / a$ & $a$ & c & $c / a$ & \\
\hline Powder & 0.42978 & 0.70134 & 1.632 & 0.42983 & 0.70116 & 1.631 & 0.42983 & 0.70116 & 1.631 & 6.73 \\
\hline 373 & 0.43033 & 0.70303 & 1.634 & 0.43047 & 0.70268 & 1.632 & 0.43073 & 0.70240 & 1.631 & 6.77 \\
\hline 473 & 0.43058 & 0.70217 & 1.631 & 0.43067 & 0.70182 & 1.630 & 0.43069 & 0.70246 & 1.631 & 6.75 \\
\hline 573 & 0.43005 & 0.70262 & 1.634 & 0.43018 & 0.70227 & 1.633 & 0.43036 & 0.70149 & 1.630 & 6.77 \\
\hline 673 & 0.43031 & 0.70247 & 1.633 & 0.43079 & 0.70241 & 1.630 & 0.43076 & 0.70167 & 1.629 & 6.78 \\
\hline 773 & 0.43061 & 0.70147 & 1.629 & 0.43135 & 0.70021 & 1.623 & 0.43166 & 0.69987 & 1.621 & 6.79 \\
\hline 873 & 0.43078 & 0.70306 & 1.632 & 0.43124 & 0.70237 & 1.629 & 0.43142 & 0.70214 & 1.628 & 6.77 \\
\hline
\end{tabular}



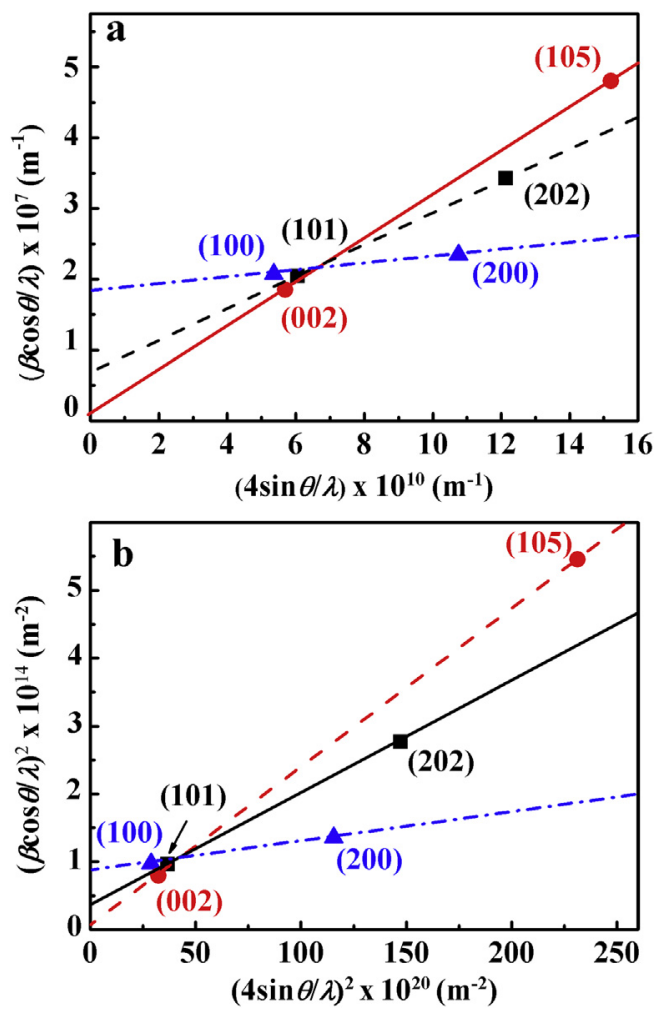

Fig. 5. Typical Hall graphs by X-ray graphs of CdSe film obtained at $T_{s}=373 \mathrm{~K}$. Cauchy (a) and Gaussian (b) approximations.

equations presented in Ref. [26]. The results of calculations are summarized in Table 2. In a most cases, the SD size and values of the micro-stress level obtained by three-fold convolution method are intermediate between the values obtained by Cauchy and Gaussian approximations. The observed good correlation indicates reliability of calculations. Further, we will discuss only the most precise results obtained by the three-fold convolution method (the calculation error for $L$ and $\varepsilon$ is less than 16\%) [44].
It could be assumed that scattering domains have a cylindrical form. The cylinders are elongated in the $c$ direction, hence the cylinder's height is along the (002) plane and its diameter coincides with (100) plane. In the case of samples obtained at lowtemperature $\left(T_{S}=373 \mathrm{~K}\right)$ the height of cylinders is about $L_{(002)} \sim 200 \mathrm{~nm}$, which is several times larger than diameter $L_{(100)} \sim 49 \mathrm{~nm}$. The diameter and height of cylinders are some changed with the substrate temperature to about 200 and $48 \mathrm{~nm}$, respectively (for the sample deposited at $T_{S}=773 \mathrm{~K}$ ). It can be explained by stacking faults formation by the analogy to $\mathrm{ZnS}$ films [25].

The micro-stress level in films is different along different crystallographic direction. In general, the micro-stress levels in the direction parallel to the $c$ crystallography axis $\left(\varepsilon_{(002)}=(0.2-4.1) \times 10^{-3}\right)$ are 2-5 times larger than for perpendicular direction $\left(\varepsilon_{(100)}=(1.1-2.8) \times 10^{-3}\right)$. Meanwhile, the behavior of $\varepsilon-T_{S}$ dependences is similar for both directions. Namely, the micro-stress levels are increase with substrate temperature till intermediate temperature range (from about 500 to $700 \mathrm{~K}$ ) then they decrease at higher temperature.

The obtained SD size $L_{(\mathrm{hhh})}=(38-200) \mathrm{nm}$ is larger than it was calculated in Refs. $[13,15]$ for the CdSe films obtained by the thermal evaporation and hot-wall epitaxy techniques. In Ref. [40] the increase in SD size from 27 to $35 \mathrm{~nm}$ within substrate temperature range from 473 to $623 \mathrm{~K}$ was observed. Work [18] reports the thickness dependence of the SD size, which varied from 2 to $42 \mathrm{~nm}$. The micro-stress level in CdSe films obtained by the vacuum evaporation presented in Ref. [40] and Ref. [41] were $\varepsilon=5.3 \times 10^{-3}$ and $\varepsilon=(2.6-6.5) \times 10^{-3}$ respectively. It should be noted that SD size and micro-stress level presented in Refs. [18,40,41] are roughly estimated, because authors did not take into account the contributions of small SD sizes and micro-strains to broadening of XRD peaks.

It should be noted that optical study of CdSe films deposited by CSVS technique at similar deposition conditions was carried out by us in Ref. [45]. There were determined optical constants and band gap values $E_{g}$. It was determined the correlation between optical quality and structural properties of CdSe films. The variation of $E_{g}$ values $\left(E_{g 1}=1.67-1.74 \mathrm{eV} ; E_{g 2}=2.06-2.13 \mathrm{eV}\right)$ may be explained

Table 2

CdSe films sub-structure characteristics.

\begin{tabular}{|c|c|c|c|c|c|c|c|}
\hline \multirow[t]{3}{*}{$T_{S}(\mathrm{~K})$} & \multirow[t]{3}{*}{$(h k l)$} & \multicolumn{3}{|l|}{$L(\mathrm{~nm})$} & \multicolumn{3}{|l|}{$\varepsilon \times 10^{3}$} \\
\hline & & \multicolumn{2}{|c|}{ Approximation by } & \multirow[t]{2}{*}{ From convolution } & \multicolumn{2}{|c|}{ Approximation by } & \multirow[t]{2}{*}{ From convolution } \\
\hline & & Gaussian & Cauchy & & Gaussian & Cauchy & \\
\hline \multirow[t]{3}{*}{ Powder } & $(100)-(200)$ & 57.8 & 72.5 & 59.9 & 1.7 & 0.8 & 1.3 \\
\hline & $(101)-(202)$ & 41.6 & 39.9 & 41.6 & 0.9 & 0.5 & 0.6 \\
\hline & $(002)-(105)$ & 52.2 & 49.2 & 52.0 & 0.7 & 0.5 & 0.5 \\
\hline \multirow[t]{3}{*}{373} & $(100)-(200)$ & 47.9 & 55.2 & 48.7 & 1.4 & 0.5 & 1.1 \\
\hline & $(101)-(202)$ & 76.6 & 154.8 & 93.2 & 2.9 & 2.3 & 2.6 \\
\hline & $(002)-(105)$ & $>200$ & $>200$ & $>200$ & 3.8 & 3.6 & 1.7 \\
\hline \multirow[t]{3}{*}{473} & $(100)-(200)$ & 50.1 & 82.3 & 56.8 & 3.2 & 2.4 & 2.8 \\
\hline & $(101)-(202)$ & 68.3 & 75.2 & 69.0 & 1.8 & 0.9 & 1.3 \\
\hline & $(002)-(105)$ & $>200$ & $>200$ & $>200$ & 1.3 & 0.4 & 0.9 \\
\hline \multirow[t]{3}{*}{573} & $(100)-(200)$ & 67.6 & 64.1 & 67.5 & 1.5 & 1.8 & 1.4 \\
\hline & $(101)-(202)$ & 36.3 & 50.7 & 38.0 & 2.2 & 3.4 & 2.8 \\
\hline & $(002)-(105)$ & $>200$ & $>200$ & $>200$ & 3.9 & 3.9 & 4.1 \\
\hline \multirow[t]{3}{*}{673} & $(100)-(200)$ & - & - & - & - & - & - \\
\hline & $(101)-(202)$ & 49.7 & 88.9 & 57.9 & 3.5 & 2.7 & 3.1 \\
\hline & $(002)-(105)$ & $>200$ & $>200$ & $>200$ & 3.4 & 3.1 & 3.4 \\
\hline \multirow[t]{3}{*}{773} & $(100)-(200)$ & $>200$ & $>200$ & $>200$ & 2.5 & 2.3 & 2.5 \\
\hline & $(101)-(202)$ & 55.5 & 59.4 & 48.1 & 0.3 & 0.1 & 0.5 \\
\hline & $(002)-(105)$ & $>200$ & $>200$ & $>200$ & 3.7 & 3.1 & 4.0 \\
\hline \multirow[t]{3}{*}{873} & $(100)-(200)$ & - & - & - & - & - & - \\
\hline & $(101)-(202)$ & 66.8 & 80.7 & 71.3 & 0.3 & 0.2 & 0.6 \\
\hline & $(002)-(105)$ & 62.2 & 64.5 & 62.3 & 0.4 & 0.1 & 0.2 \\
\hline
\end{tabular}




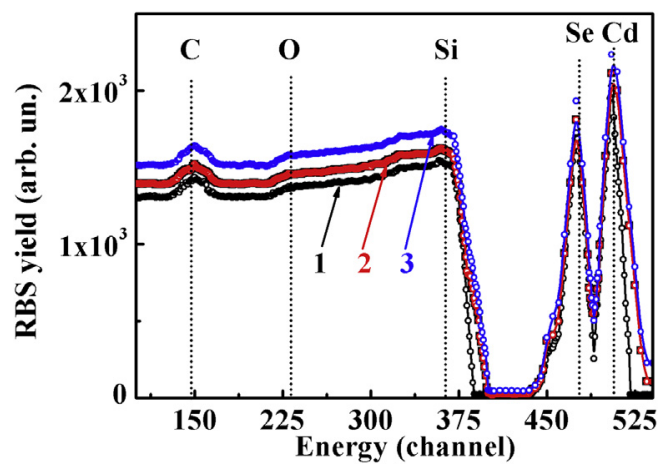

Fig. 6. RBS analysis of CdSe thin films. $T_{s}, \mathrm{~K}: 1-373 ; 2-573 ; 3-873$.

Table 3

Atomic concentrations and stoichiometric ratio of CdSe films.

\begin{tabular}{llll}
\hline$T_{s}, \mathrm{~K}$ & $C_{C d}$, at. \% & $C_{S e}$, at. \% & $\gamma$ \\
\hline 373 & 42.60 & 48.57 & 0.88 \\
573 & 44.83 & 48.96 & 0.92 \\
873 & 44.96 & 49.24 & 0.91 \\
\hline
\end{tabular}

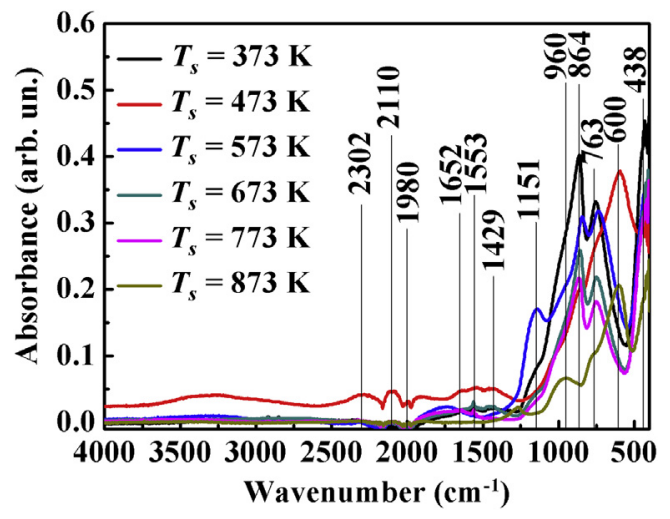

Fig. 7. FTIR spectra of CdSe thin films.

by the presence of cubic phase in these samples and by the optical transitions between the conduction and valence bands including the lower valence band [36,45].

\subsection{RBS and FTIR study}

The RBS spectra of CdSe films obtained under different deposition conditions are shown in Fig. 6. It should be noted that for the investigated films, the peaks which correspond to characteristic cadmium and selenium compound components, substrate material (glass) components - Si and $\mathrm{O}$ are observed. Besides, an additional carbon (C) impurity peak which may be present as a part of residual atmosphere or organic path on the film surface also was found [46]. The stoichiometry and the elemental composition of the films were studied using RBS spectra. Silicon ( $\mathrm{Si}$ ) and oxygen (O) peaks observed in the spectra belong to the substrate material.

Table 3 shows that the values stoichiometry $(\gamma)$ of CdSe films are better at higher substrate temperatures. Similar results were obtained in Ref. [20] where CdSe films were deposited into porous silicone matrices by isothermal close space sublimation technique.

Results of the FTIR investigation of CdSe films are presented in Fig. 7. At frequencies 436-438, 600-601 and 758-763 $\mathrm{cm}^{-1}$ a typical $\mathrm{Cd}-\mathrm{O}$ bending and $\mathrm{Cd}-$ Se stretching vibration modes are observed [46,48,53]. Other peaks are observed at 864, 960, 1151, 1459, 1553, 1652, 1980, 2110 and $2302 \mathrm{~cm}^{-1}$. The nature of these peaks presented in Table 4. It should be noted that in all cases of investigated CdSe films in the region of $\nu=(1000-2000) \mathrm{cm}^{-1}$ the peaks which are due to the $\mathrm{O}-\mathrm{H}$ and $\mathrm{CH}_{2}$ vibration modes are presented. It may be caused by the samples inhomogeneous relief due to the oxidation process. The observation of these peaks may be caused by non-uniform relief of samples surface due to the oxidation process. The presence of carbon impurities $\left(\nu=1980 \mathrm{~cm}^{-1}\right)$ is confirmed by the RBS analysis. In all investigated films there is no absorption in the spectral region $2500-3500 \mathrm{~cm}^{-1}$, which confirms the purity of the condensates without any moisture and contamination from vacuum pump oil [54].

\section{Conclusions}

In this work the investigations of the surface morphology, grown mechanisms, structural, sub-structural and IR-spectroscopy of polycrystalline CdSe thin films deposited by the close-spaced vacuum sublimation technique were performed. The structural study of CdSe films deposited by a CSVS method shows that these layers can be used in tandem solar cells for the effective light absorption in wavelength range more than $700 \mathrm{~nm}(E<1.77 \mathrm{eV})$. At the same time the films deposited at the substrate temperatures $T_{S}>573 \mathrm{~K}$ have optimal characteristics for solar cells base layer. These films are highly textured and have a single phase columnar structure with large average grain size, SD size and have a strongly pronounced pyramidal relief. It was shown that obtained films have single phase and had stable hexagonal modification and texture [002] at $T_{s} \leq 773 \mathrm{~K}$, at higher temperatures - [102]. Their crystalline size is increased with increase of the substrate temperature from $(0.1-0.3) \mu \mathrm{m}$ at $T_{s}<673 \mathrm{~K}$ till $(3-4) \mu \mathrm{m}$ at $T_{s}=873 \mathrm{~K}$. It was revealed the dependence of the lattice parameter, SDS and the micro-stress level on the substrate temperature. Physical and

Table 4

FTIR results of CdSe films.

\begin{tabular}{|c|c|c|c|c|c|c|c|c|c|c|c|c|c|}
\hline \multicolumn{2}{|c|}{$T_{s}=373 \mathrm{~K}$} & \multicolumn{2}{|c|}{$T_{s}=473 \mathrm{~K}$} & \multicolumn{2}{|c|}{$T_{s}=573 \mathrm{~K}$} & \multicolumn{2}{|c|}{$T_{s}=673 \mathrm{~K}$} & \multicolumn{2}{|c|}{$T_{s}=773 \mathrm{~K}$} & \multicolumn{2}{|c|}{$T_{s}=873 \mathrm{~K}$} & \multirow[t]{2}{*}{ Assignment } & \multirow[t]{2}{*}{ [Ref.] } \\
\hline$\nu, \mathrm{cm}^{-1}$ & $E, \mathrm{eV}$ & $\nu, \mathrm{cm}^{-1}$ & $E, \mathrm{eV}$ & $\nu, \mathrm{cm}^{-1}$ & $E, \mathrm{eV}$ & $\nu, \mathrm{cm}^{-1}$ & $E, \mathrm{eV}$ & $\nu, \mathrm{cm}^{-1}$ & $E, \mathrm{eV}$ & $\nu, \mathrm{cm}^{-1}$ & $E, \mathrm{eV}$ & & \\
\hline 2302 & 0.285 & 2302 & 0.285 & 2302 & 0.285 & 2302 & 0.285 & 2302 & 0.285 & 2302 & 0.285 & $\mathrm{NO}^{+}$nitrozyle & {$[46]$} \\
\hline 2110 & 0.262 & 2110 & 0.262 & 2110 & 0.262 & 2108 & 0.261 & 2110 & 0.262 & 2105 & 0.261 & C-O stretch & {$[47]$} \\
\hline 1652 & 0.205 & 1652 & 0.205 & - & - & - & - & - & - & - & - & $\mathrm{O}-\mathrm{H}$ bending & [48] \\
\hline- & - & - & - & - & - & 1553 & 0.193 & 1553 & 0.193 & - & - & $\mathrm{COO}^{-}$stretch & [49] \\
\hline 1429 & 0.177 & 1430 & 0.177 & 1430 & 0.177 & - & - & - & - & - & - & $\mathrm{N}-\mathrm{C}$ stretch & {$[50]$} \\
\hline 1151 & 0.143 & - & - & 1148 & 0.142 & - & - & - & - & - & - & $\mathrm{CH}_{2}$ vibration & [51] \\
\hline 762 & 0.094 & 760 & 0.094 & 763 & 0.095 & 763 & 0.095 & 758 & 0.094 & 760 & 0.094 & Cd-Se stretch & [53] \\
\hline 601 & 0.075 & - & - & - & - & - & - & - & - & 600 & 0.074 & Cd-Se stretch & [48] \\
\hline 436 & 0.054 & 438 & 0.054 & 438 & 0.054 & 436 & 0.054 & 438 & 0.054 & 438 & 0.054 & $\mathrm{Cd}-\mathrm{O}$ bending & {$[46]$} \\
\hline
\end{tabular}


technological deposition regimes of CdSe films for use as absorption layers of tandem hetero-junction solar converters were estimated.

\section{Acknowledgments}

This research was supported by the Ministry of Education and Science of Ukraine (Grant № 0113U000131).

\section{References}

[1] Mahawela P, Jeedigunta S, Vakkalanka S, Ferekides CD, Morel DL. Thin Solid Films 2005;480:466.

[2] Mahawela P, Sivaraman G, Jeedigunta S, Gaduputi J, Ramalingam M, Subramanian S, et al. Mater Sci Eng B 2005;116:283.

[3] Hangarter MC, Debnath R, Ha JY, Sahiner MA, Reehil CJ, Manners WA, et al. ACS Appl Mater Interfaces 2013;5:9120.

[4] Oertel DC, Bawendi MG, Arango AC, Bulovic V. Appl Phys Lett 2005;87: 213505.

[5] Dondapati H, Ha D, Pradhan AK. Appl Phys Lett 2013;103:121114.

[6] Belkouch S, Landheer D, Masson DP, Das SR, Quance T, Vac J. Sci Technol A 1998;16:860.

[7] Kasap S. In: Capper P, editor. Springer handbook of electronic and photonic materials. Berlin: Springer; 2007. p. 1407.

[8] Patil SA, Shinde DV, Bhande SS, Jadhav VV, Huan TN, Mane RS, et al. Dalton Trans 2013;42:13065.

[9] Ohring M. The materials science of thin films. New York: Academic Press; 1992. 704 p.

[10] Wang X, Li R, Fan D. Nanoscale Res Lett 2011;6:614.

[11] Deshpande MP, Garg N, Bhatt SV, Sakarija P, Chaki SH. Mater Sci Semicond Proc 2013;16:915.

[12] Gopakumar N, Anjana PS, Vidjadharan Pillai PK. J Mater Sci 2010;45:6653.

[13] Kale RB, Lokhande CD. Semicond Sci Technol 2005;20:1.

[14] Ichimura M, Takeuchi K, Nakamura A, Arai E. Thin Solid Films 2001;384:157.

[15] Kokate AV, Suryavanshi UB, Bhosale CH. Sol Energy 2006;80:156.

[16] Swaminathan V, Subramanian V, Murali KR. Thin Solid Films 2000;359:113.

[17] Grün M, Becker U, Scheib M, Giessen H, Klingshirn G. J Cryst Growth 1993; 126:505.

[18] Velumani S, Narayandass SaK, Mangalarai D. Semicond Sci Technol 1998;13: 1016.

[19] Larramendi EM, Gutierrez Z-BK, de Melo O, Woggon U, Schikora D, Lischka K. J Cryst Growth 2010;312:1807.

[20] Torres-Costa V, de Melo C, Climent-Font A, Argullo-Lueda F, de Melo O. Nanoscale Res Lett 2012;7:409.

[21] Baban C, Rusu GI. Appl Surf Sci 2003;211:6.

[22] Baban C, Caraman M, Rusu GI. J Optoelectron Adv Mater 2006;8:917.

[23] Ciupina V, Petcu A, Rambu P, Baban C, Petcu LC, Prodan G, et al. J Optoelectron Adv Mater 2008;10(11):2993.
[24] Kosyak VV, Opanasyuk AS, Bukivskij PM, Gnatenko YuP. J Cryst Growth 2010;312:1726.

[25] Kurbatov D, Khlyap H, Opanasyuk A. Phys Status Solidi A 2009;206:1549.

[26] Kurbatov D, Kosyak V, Kolesnyk M, Opanasyuk A, Danilchenko S. Integr Ferroelectr 2009;103:32.

[27] Kurbatov DI, Kosyak VV, Kolesnyk MM, Opanasyuk AS, Danilchenko SN, Gnatenko YuP. Mater Chem Phys 2013;138(2-3):731.

[28] Kosyak VV, Kolesnik MM, Opanasyuk AS. J Mater Sci Mater Electr 2008;19(1): S375.

[29] Gnatenko YuP, Bukivskij PM, Opanasyuk AS, Kurbatov DI, Kolesnyk MM, Kosyak VV, et al. J Lumin 2012;132:2885.

[30] Suryanarayana C. Experimental techniques in materials and mechanics. CRC Press; 2011. 95 p.

[31] Selected powder diffraction data for education and training (search manual and data cards). USA: International Centre for Diffraction Data; 1988.

[32] Harris GB. Philos Mag 1953;43(1):113.

[33] Warren BE. X-ray diffraction. New York: Dover; 1990. p. 369.

[34] Bowen DK, Brian Tanner K. X-ray metrology in semiconductor manufacturing. Oxford: Taylor \& Francis Group; 2006. 296 p.

[35] Kurbatov D, Opanasyuk A, Duvanov SM, Balogh AG, Khlyap H. Solid State Sci $2011 ; 13: 1068$

[36] Bacaksiz E, Basol BM, Altunbas M, Yilmaz S, Tomakin M, Abay B. Phys Status Solidi A 2007:244:497.

[37] Mahieu S, Ghekiere P, Depla D, de Gryse R. Thin Solid Films 2006;515:1229.

[38] Luschitz J, Lakus-Wollny K, Klein A, Jaegermann W. Thin Solid Films 2007;515: 5814.

[39] Ion L, Antohe VA, Antohe S. J Optoelectron Adv Mater 2005;4:1847.

[40] Antohe S, Ruxandra V, Alexandru H. Cryst Res Technol 2002;237-239:1559.

[41] Sarman K, Sarma R, Das HL. Chalcogenide Lett 2008;5:153.

[42] Patel KD, Jani MS, Pathak VM, Srivastava R. Chalcogenide Lett 2009;6:279.

[43] Gnatenko YuP, Bukivskij PM, Faryna IO, Opanasyuk AS, Ivashchenko MM. J Lumin 2014;146:174.

[44] Danilchenko SN, Kukharenko OG, Moseke C, Protsenko IYu, Sukhodub LF, Sulkio-Cleff B. Cryst Res Technol 2002:37:1234.

[45] Starikov VV, Ivashchenko MM, Opanasyuk AS, Perevertaylo VL. J Nano Electron Phys 2009;1(4):119.

[46] Nakamoto K. Infrared and Raman spectra of inorganic and coordination compounds. Part A. Theory and applications in inorganic chemistry. 6th ed. Weinheim, Germany: Wiley; 2009. 432 p.

[47] Ivashchenko MM, Buryk IP, Opanasyuk AS, Nam D, Cheong H, Vaziev JaG, et al. Mater Sci Semicon Proc 2015:36:13.

[48] Acharya A, Mishra R, Roy GS. Lat Am J Phys Educ 2010;4(3):603.

[49] Mehta C, Abbas JM, Saini JSS, Tripathi SK. Chalcogenide Lett 2007;4(11):133.

[50] Chae DY, Seo KW, Lee SS, Yoon SH, Shim I-W. Bull Korean Chem Soc 2006;27(5):762.

[51] Deo SR, Singh AK, Deshmukh L, Paliwal LJ, Singh RS, Adhikari R. J Saudi Chem Soc 2014. http://dx.doi.org/10.1016/j.jscs.2014.01.005.

[52] Goncalves LFFF, Silva CJR, Kanodarwala FK, Stride JA, Pereira MR, Gomes MJM. Mater Chem Phys 2014. http://dx.doi.org/10.1016/j.matchemphys.2014.04. 010.

[53] Chikate RC, Kadu BS. Spectrochim Acta A 2014;124:138.

[54] Rani S, Shanthi J. Int J Sci Res 2014;3(2):320. 